BRAVILLIAN JOURNAL

www.bjournal.com.br
ISSN 0100-879X

Volume 43 (4) 268-380 April 2011

BIOMEDICAL SCIENCES

AND

CLINICAL INVESTIGATION

Braz J Med Biol Res, April 2011, Volume 44(4) 354-360

doi: 10.1590/S0100-879X2011007500023

Relationship between work rate and oxygen uptake in mitochondrial myopathy during ramp-incremental exercise

A.C. Gimenes, J.A. Neder, S. Dal Corso, C.R. Nogueira, L. Nápolis, M.T. Mello, A.S. Bulle and L.E. Nery

The Brazilian Journal of Medical and Biological Research is partially financed by

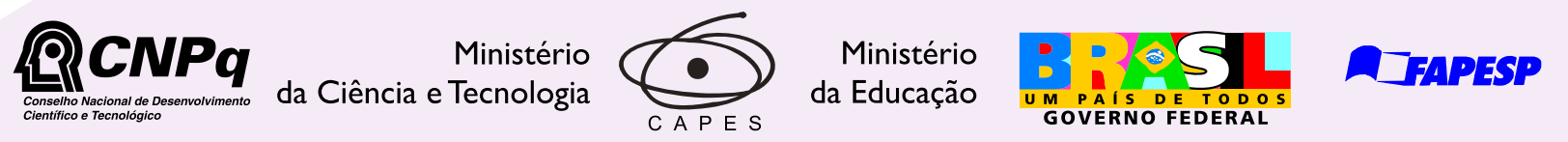

Institutional Sponsors
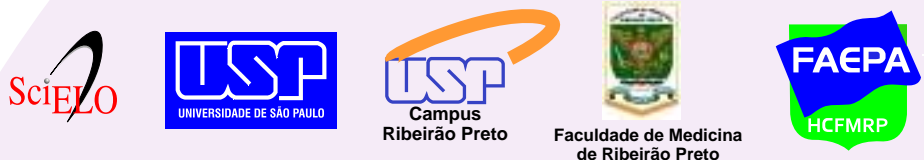


\title{
Relationship between work rate and oxygen uptake in mitochondrial myopathy during ramp-incremental exercise
}

\author{
A.C. Gimenes ${ }^{1}$, J.A. Neder ${ }^{1}$, S. Dal Corso ${ }^{1}$, C.R. Nogueira ${ }^{1}$, L. Nápolis ${ }^{1}$, \\ M.T. Mello ${ }^{3}$, A.S. Bulle ${ }^{2}$ and L.E. Nery ${ }^{1}$ \\ 1Setor de Fisiologia Clínica do Exercício, Disciplina de Pneumologia, Departamento de Medicina, \\ ${ }^{2}$ Setor de Doenças Neuromusculares, ${ }^{3}$ Departamento de Psicobiologia, Escola Paulista de Medicina, \\ Universidade Federal de São Paulo, São Paulo, SP, Brasil
}

\begin{abstract}
We determined the response characteristics and functional correlates of the dynamic relationship between the rate $(\Delta)$ of oxygen consumption $\left(\mathrm{VO}_{2}\right)$ and the applied power output (work rate $=\mathrm{WR}$ ) during ramp-incremental exercise in patients with mitochondrial myopathy (MM). Fourteen patients (7 males, age $35.4 \pm 10.8$ years) with biopsy-proven MM and 10 sedentary controls ( 6 males, age $29.0 \pm 7.8$ years) took a ramp-incremental cycle ergometer test for the determination of the $\mathrm{VO}_{2}$ on-exercise mean response time (MRT) and the gas exchange threshold (GET). The $\Delta \mathrm{VO}_{2} / \Delta \mathrm{WR}$ slope was calculated up to GET $\left(S_{1}\right)$, above GET $\left(S_{2}\right)$ and over the entire linear portion of the response $\left(S_{T}\right)$. Knee muscle endurance was measured by isokinetic dynamometry. As expected, peak $\mathrm{VO}_{2}$ and muscle performance were lower in patients than controls $(\mathrm{P}<0.05)$. Patients had significantly lower $\Delta \mathrm{VO}_{2} / \Delta \mathrm{WR}$ than controls, especially the $S_{2}$ component $\left(6.8 \pm 1.5 \mathrm{vs} 10.3 \pm 0.6 \mathrm{~mL} \cdot \mathrm{min}^{-1} \cdot \mathrm{W}^{-1}\right.$, respectively; $\left.\mathrm{P}<0.001\right)$. There were significant relationships between $\Delta \dot{V O}_{2} / \Delta \mathrm{WR}\left(\mathrm{S}_{T}\right)$ and muscle endurance, $\mathrm{MRT}-\mathrm{VO}_{2}$, GET and peak $\mathrm{VO}_{2}$ in $\mathrm{MM}$ patients $(P<0.05)$. In fact, all patients with $\Delta \mathrm{VO}_{2} / \Delta \mathrm{WR}$ below $8 \mathrm{~mL} \cdot \mathrm{min}^{-1} \cdot \mathrm{W}^{-1}$ had severely reduced peak $\mathrm{VO}_{2}$ values $(<60 \%$ predicted). Moreover, patients with higher cardiopulmonary stresses during exercise (e.g., higher $\Delta$ ventilation/carbon dioxide output and $\Delta$ heart rate/ $\left.\Delta \mathrm{VO}_{2}\right)$ had lower $\Delta \mathrm{VO}_{2} / \Delta \mathrm{WR}(\mathrm{P}<0.05)$. In conclusion, a readily available, effort-independent index of aerobic dysfunction during dynamic exercise $\left(\Delta \mathrm{VO}_{2} / \Delta \mathrm{WR}\right)$ is typically reduced in patients with $\mathrm{MM}$, being related to increased functional impairment and higher cardiopulmonary stress.
\end{abstract}

Key words: Muscular diseases; Oxygen consumption; Cardiopulmonary exercise testing; Skeletal muscle; Pathophysiology; Mitochondrial myopathy

\section{Introduction}

The rate $(\Delta)$ of change in oxygen consumption $\left(\mathrm{VO}_{2}\right)$ relative to power output (work rate, WR) during rampincremental exercise depends on the ability of the cardiocirculatory system to deliver, and the muscle capacity to extract, $\mathrm{O}_{2}$ from arterial (capillary) blood $(1,2)$. The $\Delta \mathrm{VO}_{2} /$ $\triangle W R$ relationship is influenced by the gas exchange threshold (GET) with most investigators describing a bi-linear response, i.e., a sub-GET $S_{1}$ slope flatter than a supra-GET $S_{2}$ slope (3-5). The analysis of the total $\Delta \mathrm{VO}_{2} / \Delta \mathrm{WR}$ slope $\left(S_{T}\right)$ and its components can provide useful information about the adequacy of the aerobic responses to exercise in health and disease. Several studies, for instance, have shown that a flatter-than-normal $\Delta \mathrm{VO}_{2} / \Delta \mathrm{WR}$ is a sensitive marker of abnormal $\mathrm{O}_{2}$ delivery and utilization in a number of systemic pathological conditions ranging from congestive heart failure to systemic lupus erythematosus (6-11).

Mitochondrial diseases are caused by very diverse genetic alterations located either on nuclear DNA or on mitochondrial DNA (mtDNA) (12). Mitochondrial myopathy $(\mathrm{MM})$ is the collective term for disease conditions in which the diminished rate of cellular $\mathrm{O}_{2}$ utilization may place a burden on several systems in order to enhance $\mathrm{O}_{2}$ uptake and delivery (13-15). In fact, patients with MM commonly present hyperventilatory and hypercirculatory patterns of response to dynamic exercise (16-20). These abnormalities are likely to be related to the fundamental pathophysiological abnormality in $\mathrm{MM}$, i.e., impaired $\mathrm{O}_{2}$ extraction. In this context, although there is a sound physiological rationale

Correspondence: L.E. Nery, SEFICE, EPM, UNIFESP, Rua Professor Francisco de Castro, 54, 04020-050 São Paulo, SP, Brasil.

Fax: +55-11-5575-2843. E-mail: lenery@pneumo.epm.br

Received June 24, 2010. Accepted February 16, 2011. Available online March 4, 2011. Published April 11, 2011. 
for the notion that $\Delta \mathrm{VO}_{2} / \Delta \mathrm{WR}$ would be severely reduced in $\mathrm{MM}$, and probably related to exercise impairment and to systemic cardiopulmonary stress, no previous study has investigated the characteristics and functional correlates of $\Delta \mathrm{VO}_{2} / \Delta \mathrm{WR}\left(S_{1}, S_{2}, S_{T}\right)$ in this patient population.

The objective of this study, therefore, was to compare the dynamic behavior of $\Delta \mathrm{VO}_{2} / \Delta \mathrm{WR}$ during ramp-incremental exercise of patients with $\mathrm{MM}$ and that of healthy sedentary controls. We hypothesized that patients would present impaired $\mathrm{O}_{2}$ utilization (reduced $\Delta \mathrm{VO}_{2} / \Delta \mathrm{WR}$ ), which would be significantly related to maximum exercise capacity and selected indexes of functional impairment. In addition, we anticipated that the ventilatory and cardiovascular responses to the prevailing metabolic demand (21-23) would be inversely related to $\Delta \mathrm{VO}_{2} / \Delta \mathrm{WR}$, suggesting that the hyperkinetic cardiopulmonary response would be mechanistically linked to impaired muscle bioenergetics in MM.

\section{Material and Methods}

\section{Study population}

Fourteen non-smoking patients (7 males aged 20 to 52 years) with biopsy-proven MM (see below) who had been followed at the Institutional Neuromuscular Division agreed to participate in the study. All consecutive patients with the following characteristics were selected: clinical evidence of MM in the form of chronic progressive external ophthalmoplegia $(13,17)$ : ptosis, exercise intolerance, and chronic fatigue. This phenotype is associated with autosomal dominant DNA polymerase-gamma and adenine nucleotide translocase mutations with consequent deletions in mtDNA (15). There was no clinical or echocardiographic evidence of cardiomyopathy or impaired cardiac conduction in any patient. Subjects with mitochondrial encephalomyopathy, lactic acidosis and strokes, myoclonus epilepsy with ragged-red fibers, and other MMs were excluded from the study. In addition, to avoid the confounding effect of physical conditioning on muscle metabolism in MM (24), we selected patients who had not engaged in any regular physical activity in the preceding year.

Ten age- and gender-matched healthy volunteers (6 males aged 20 to 46 years) comprised the control group. In order to match patients and controls for habitual physical activity, all study participants were required to present very low daily physical activity scores according to the Baecke questionnaire (total score <6) (25). The experimental protocol was approved by the Institutional Ethics Committee. However, muscle biopsies from normal subjects were not permitted. Written informed consent to participate was obtained from each subject.

\section{Measurements}

Body composition. Mid-arm circumference was measured and skin fold thickness at the bicipital and tricipital levels was obtained using a skin fold caliper: arm muscle circumference was derived from these readings $(\mathrm{cm})$. Bioelectrical impedance (Quantum BIA-101Q, RJL-101 TM USA) was used to estimate total body fat-free mass (FFM, $\mathrm{kg}$ ); FFM index (FFMI) was calculated as the ratio of FFM to height in meters squared.

Skeletal muscle biopsies. Percutaneous biopsies of the right vastus lateralis were obtained from its central region, $10-15 \mathrm{~cm}$ above the patella at mid-thigh level in patients. The biopsies were taken at least 3 months before the exercise test. Histopathological evaluation revealed a ragged-red fiber pattern in all specimens; abnormally low mitochondrial electron transport chain activity (cytochrome c oxidase) was demonstrated histochemically by the method of Seligman et al. (26). Two experienced neuropathologists independently reviewed the muscle biopsies.

Peripheral muscle strength. Isokinetic muscle endurance of the dominant knee extensor (quadriceps) was measured with a computer-based dynamometer (Contrex CE, Switzerland). During the tests, subjects were seated upright on the chair of the dynamometer with their back fully supported. The mechanical axis of rotation of the lever arm was aligned to the axis of rotation of the knee. After a 3-min rest, muscle endurance was determined as the total work achieved during 20 consecutive maximal repetitions at $300 \%$ s.

Cardiopulmonary exercise testing. The exercise tests were carried out on an electromagnetically braked cycle ergometer (CPE 2000, Medical Graphics Corporation - MGC, USA) with gas exchange and ventilatory variables being analyzed breath-by-breath $\left(\mathrm{CardiO}_{2}\right.$ System, MGC). The power (W) was continuously increased in a linear "ramp" pattern (27) $(5-15 \mathrm{~W} / \mathrm{min}$ in patients and 15-25 W/min in healthy subjects) so that the incremental exercise test duration was more than $8 \mathrm{~min}$ and less than $12 \mathrm{~min}$ in all participants, based on a "symptom-limited interruption". The following variables are reported as means of $15 \mathrm{~s}$ : oxygen uptake $\left(\mathrm{VO}_{2}, \mathrm{~L} / \mathrm{min}\right.$ at standard temperature and pressure dry, STPD), carbon dioxide output ( $\mathrm{VCO}_{2}$, L/min STPD), minute ventilation (VE, L/min BTPS), and end-tidal partial pressure for $\mathrm{O}_{2}$ and $\mathrm{CO}_{2}\left(\mathrm{PETO}_{2}\right.$ and $\left.\mathrm{PETCO} 2, \mathrm{mmHg}\right)$. Heart rate (HR, bpm) was automatically calculated from the $\mathrm{R}-\mathrm{R}$ distance of a 12-lead ECG tracing $\left(\mathrm{CardiO}_{2}\right.$ System, MGC). Capillary samples were collected from the ear lobe for blood lactate measurements $(\mathrm{mEq} / \mathrm{L})$ at exercise cessation (Yellow Springs 2.700 STAT plus, Yellow Springs Instruments, USA). The samples were lysed before the measurements and values are reported as absolute values and related to peak WR (lactate/WR ratio). The $\mathrm{VO}_{2}$ at the estimated lactate threshold was evaluated by the gas exchange method (GET), with visual inspection of the inflection point of $\mathrm{VCO}_{2}$ with regard to $\mathrm{VO}_{2}$ (modified $\mathrm{V}$-slope) and by the ventilatory method when $\mathrm{VE} / \mathrm{VO}_{2}$ and $\mathrm{PETO}_{2}$ increased while $\mathrm{VE} / \mathrm{VCO}{ }_{2}$ and $\mathrm{PETCO} \mathrm{C}_{2}$ remained stable $(28,29)$. The average $\mathrm{VO}_{2}$ for the last $15 \mathrm{~s}$ was considered to be representative of the subject's peak $\mathrm{VO}_{2}(29)$. 
In order to measure the kinetics of the initial $\mathrm{VO}_{2}$ adjustment during the incremental exercise, the mean response time (MRT) was determined as the time from the onset of the ramp forcing function to the point of intersection between the baseline $\mathrm{VO}_{2}$ and a linear backward extrapolation of the $\mathrm{VO}_{2}$ vs time slope (Figure 1) $(30,31)$. This was performed in two ways, using either the region of $\mathrm{VO}_{2}$ response below the GET, $S_{1}\left(M_{R} T_{1}\right)$, or the total slope $S_{T}\left(M R T_{T}\right)(27)$. The baseline was defined as the average value for $\mathrm{VO}_{2}$ during the last 2 min of unloaded cycling prior to onset of the ramp.

Submaximal exercise relationships. As mentioned, the $\Delta \mathrm{VO}_{2} / \Delta \mathrm{WR}$ relationship $\left(\mathrm{mL} \cdot \mathrm{min}^{-1} \cdot \mathrm{W}^{-1}\right)$ was calculated to obtain an index of the overall gain of the $\mathrm{VO}_{2}$ response, i.e., in disease states, reduced values would indicate a greater reliance on anaerobic sources of ATP regeneration $(1,2)$. Considering that the GET could distort the linearity of the response (due to an even greater reliance on anaerobic metabolism) $(3,5)$, the $\Delta \mathrm{VO}_{2} / \Delta W R$ slope was determined using linear regression analysis over three segments: $S_{1}$, from the start of $\mathrm{VO}_{2}$ increase during exercise to the GET; $S_{2}$, from the GET to either peak $\mathrm{VO}_{2}$ or where $\mathrm{VO}_{2}$ began to level off, and $S_{T}$, over the range of $S_{1}+S_{2}$.

Determination of the $\Delta H R / \Delta \mathrm{VO}_{2}$ relationship (beat $\left.L^{-1} \cdot m^{-1}\right)$. Although $\mathrm{VO}_{2}$ is an appropriate dependent variable, this relationship has been traditionally described with HR on the y-axis $(22,23)$. In this context, a steeper HR response to a given metabolic demand would imply reduced stroke volume and/or low peripheral oxygen extraction (i.e., an inappropriate cardiovascular response to incremental exercise). Linearity of the HR response throughout the test duration was first investigated for each subject. In the event of late departures from linearity, we then applied regression analysis only to the initial linear phase response.

Determination of the sub-respiratory compensation point (RCP) $\triangle \mathrm{VE} / \triangle \mathrm{VCO}_{2}$ relationship. For the determination of this index of ventilatory "efficiency" (21-23), linear regression analysis was applied only to the individually selected data points below the RCP (i.e., before the development of the characteristic hyperventilatory response to the ongoing lactacidemia).

\section{Statistical analysis}

Means and standard deviations (SD) of normally distributed data (Kolmogorov-Smirnov test) were obtained for patients and controls and were compared using an unpaired $t$-test. Alternatively, the Mann-Whitney test was used to assess between-group differences of variables with a non-Gaussian distribution. Pearson's product-moment correlation was used to assess the degree of association between continuous variables. The probability of a type I error was set at $5 \%$ for all tests $(P<0.05)$.

\section{Results}

\section{Patient characteristics \\ Patients with MM presented decreased total body and}

fat-free mass indexes compared to normal subjects $(P<$ $0.05)$. Appendicular muscle mass, estimated by arm muscle circumference, was reduced in patients (Table 1). Muscle endurance capacity (total work) was also significantly lower in patients than controls $(863.4 \pm 274.2$ vs $1577.5 \pm 450.0$ $\mathrm{kJ}$, respectively; $\mathrm{P}<0.01)$. Peripheral muscle performance was related to fat-free mass index in MM patients $(R=$ $0.74 ; \mathrm{P}<0.001)$.

\section{Metabolic responses to exercise}

There were no significant between-group differences in

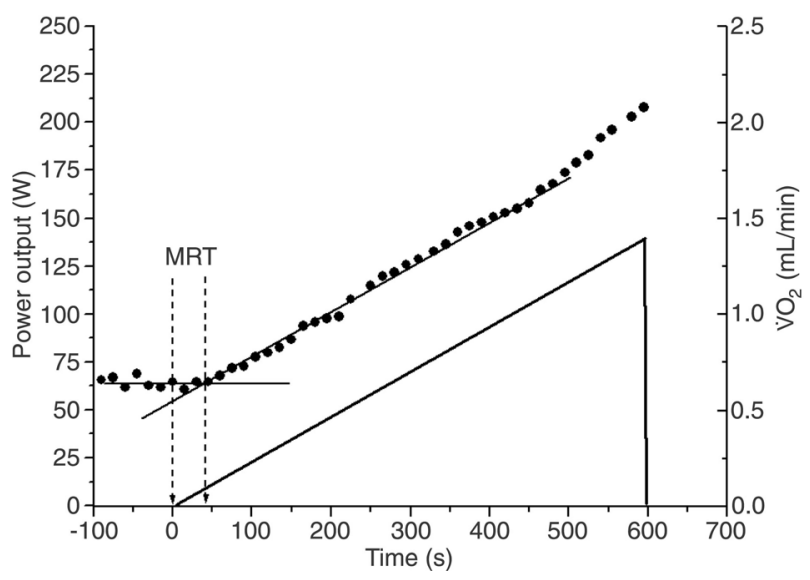

Figure 1. Oxygen uptake $\left(\mathrm{VO}_{2}\right)$ response to ramp-incremental exercise of a representative normal subject. Mean response time (MRT) of the kinetic response is calculated as the time from the onset of the ramp forcing function to the point of intersection between the baseline $\mathrm{VO}_{2}$ and a linear backward extrapolation of the $\mathrm{VO}_{2}$ vs time slope $(30,31)$.

Table 1. Resting characteristics of patients with mitochondrial myopathy and healthy controls.

\begin{tabular}{lcc}
\hline & $\begin{array}{c}\text { Mitochondrial } \\
\text { myopathy }(\mathrm{N}=14)\end{array}$ & $\begin{array}{c}\text { Controls } \\
(\mathrm{N}=10)\end{array}$ \\
\hline $\begin{array}{l}\text { Demographic/anthropometric } \\
\text { Gender (male/female) }\end{array}$ & $7 / 7$ & $6 / 4$ \\
Age (years) & $35.4 \pm 10.8$ & $29.0 \pm 7.8$ \\
Height $(\mathrm{m})$ & $1.61 \pm 0.83^{*}$ & $1.70 \pm 0.64$ \\
Weight $(\mathrm{kg})$ & $52.9 \pm 13.5^{*}$ & $71.4 \pm 9.8$ \\
Body composition & & \\
BMI $\left(\mathrm{kg} / \mathrm{m}^{2}\right)$ & $19.9 \pm 3.9^{*}$ & $24.6 \pm 2.9$ \\
FFM $(\mathrm{kg})$ & $40.3 \pm 8.7^{*}$ & $52.5 \pm 7.1$ \\
FFM index $\left(\mathrm{kg} / \mathrm{m}^{2}\right)$ & $15.3 \pm 2.3^{*}$ & $18.0 \pm 2.0$ \\
AMC $(\mathrm{cm})$ & $20.5 \pm 2.6^{*}$ & $24.9 \pm 4.7$ \\
\hline
\end{tabular}

Data are reported as means $\pm \mathrm{SD}$. BMI = body mass index; FFM = fat free mass; $A M C=$ arm muscle circumference. ${ }^{*} \mathrm{P}<0.05$ (unpaired $t$-test). 
duration of the ramp forcing protocol $(8.6 \pm 1.1 \mathrm{vs} 8.9 \pm 1.9$ min for patients and controls, respectively; $P>0.05)$. Peak $\mathrm{VO}_{2}$ and power (WR) were significantly lower in patients than controls (Table 2). The GET was noninvasively identified in all subjects and was lower in patients than controls when analyzed as $\mathrm{mL} / \mathrm{min}$ and as $\%$ of predicted; however, since patients had lower weight, GET in $\mathrm{mL} \cdot \mathrm{min}^{-1} \cdot \mathrm{kg}^{-1}$ was

Table 2. Cardiopulmonary exercise variables of patients with mitochondrial myopathy and healthy controls.

\begin{tabular}{|c|c|c|}
\hline & $\begin{array}{c}\text { Mitochondrial } \\
\text { myopathy }(\mathrm{N}=14)\end{array}$ & $\begin{array}{l}\text { Controls } \\
(\mathrm{N}=10)\end{array}$ \\
\hline \multicolumn{3}{|l|}{ POWER } \\
\hline Peak WR (W) & $91 \pm 31^{*}$ & $178 \pm 38$ \\
\hline \multicolumn{3}{|l|}{ METABOLIC } \\
\hline \multicolumn{3}{|l|}{ Peak exercise } \\
\hline$\ddot{\mathrm{VO}} 2\left(\mathrm{~mL} \cdot \mathrm{min}^{-1} \cdot \mathrm{kg}^{-1}\right)$ & $22.3 \pm 7.2^{*}$ & $30.7 \pm 6.0$ \\
\hline $\mathrm{VO}_{2}(\%$ pred $)$ & $64 \pm 21^{*}$ & $95 \pm 15$ \\
\hline RER & $1.19 \pm 0.15$ & $1.20 \pm 0.08$ \\
\hline Lactate (mM) & $7.2 \pm 2.1$ & $7.4 \pm 1.4$ \\
\hline Lactate/WR (mM/W) & $0.07(0.03-0.17)^{*}$ & $0.04(0.03-0.06)$ \\
\hline \multicolumn{3}{|c|}{ At the gas exchange threshold (GET) } \\
\hline $\mathrm{VO}_{2}(\mathrm{~mL} / \mathrm{min})$ & $705 \pm 274^{*}$ & $1006 \pm 267$ \\
\hline $\mathrm{VO}_{2}\left(\mathrm{~mL} \cdot \mathrm{min}^{-1} \cdot \mathrm{kg}^{-1}\right)$ & $13.11 \pm 3.40$ & $14.26 \pm 3.55$ \\
\hline $\mathrm{VO}_{2}\left(\% \mathrm{VO}_{2}\right.$ peak $)$ & $60.8 \pm 9.3^{*}$ & $46.7 \pm 7.9$ \\
\hline \multicolumn{3}{|l|}{ Submaximal relationship } \\
\hline \multicolumn{3}{|l|}{$\Delta \mathrm{VO}_{2} / \Delta \mathrm{WR}\left(\mathrm{mL} \cdot \mathrm{min}^{-1} \cdot \mathrm{W}^{-1}\right)$} \\
\hline$S_{1}$ & $7.8 \pm 1.4^{*}$ & $9.5 \pm 0.8$ \\
\hline$S_{2}$ & $6.8 \pm 1.5^{\star}$ & $10.3 \pm 0.6$ \\
\hline$S_{T}$ & $7.4 \pm 1.7^{*}$ & $9.9 \pm 0.7$ \\
\hline \multicolumn{3}{|l|}{$\mathrm{VO}_{2} \mathrm{KINETICS}$} \\
\hline MRT1 (s) & $56.2 \pm 17.4^{*}$ & $47.1 \pm 18.0$ \\
\hline MRT2 (s) & $58.7 \pm 19.2^{*}$ & $49.3 \pm 17.4$ \\
\hline \multicolumn{3}{|l|}{ VENTILATORY } \\
\hline \multicolumn{3}{|l|}{ Peak exercise } \\
\hline VE (L/min) & $41.9 \pm 17.7^{\star}$ & $81.6 \pm 20.9$ \\
\hline \multicolumn{3}{|l|}{ Submaximal relationship } \\
\hline$\Delta \ddot{\mathrm{VE}} / \Delta \mathrm{VCO}_{2}(\mathrm{~L} / \mathrm{L})$ & $36.5 \pm 5.2^{*}$ & $27.3 \pm 2.7$ \\
\hline \multicolumn{3}{|l|}{ CARDIOVASCULAR } \\
\hline \multicolumn{3}{|l|}{ Peak exercise } \\
\hline $\mathrm{HR}(\mathrm{bpm})$ & $157 \pm 19^{*}$ & $178 \pm 10$ \\
\hline HR (\% pred) & $86.3 \pm 8.1^{*}$ & $95.4 \pm 4.3$ \\
\hline $\mathrm{VO}_{2} / \mathrm{HR}\left(\mathrm{mL} \cdot \mathrm{min}^{-1} \cdot\right.$ beat $\left.^{-1}\right)$ & $7.4 \pm 3.1^{*}$ & $11.4 \pm 3.3$ \\
\hline \multicolumn{3}{|l|}{ Submaximal relationship } \\
\hline$\Delta \mathrm{HR} / \Delta \mathrm{VO}_{2}\left(\right.$ beat $\left.\cdot \mathrm{L}^{-1} \cdot \mathrm{min}^{-1}\right)$ & $83.0 \pm 26.2^{*}$ & $54.4 \pm 14.8$ \\
\hline
\end{tabular}

Data are reported as means $\pm \mathrm{SD}$ or median (range). $\mathrm{WR}=$ work rate; $\mathrm{RER}=$ respiratory exchange ratio, $\mathrm{VO}_{2}=$ oxygen uptake; $\mathrm{MRT}=$ mean response time; $\mathrm{VE}=$ minute ventilation; $\mathrm{HR}=$ heart rate; $\mathrm{VCO}_{2}=$ carbon dioxide output. ${ }^{*} \mathrm{P}<$ 0.05 (unpaired $t$-test or Mann-Whitney test). not significantly different. Also, patients had a lower capacity to sustain exercise performance after the GET through peak $\mathrm{VO}_{2}$, which was related to symptoms of leg pain and dyspnea. Therefore, the $\mathrm{GET} / \mathrm{VO}_{2}$ peak ratio was higher in $\mathrm{MM}$ patients compared to controls.

The $\Delta \mathrm{VO}_{2} / \Delta \mathrm{WR}$ relationship could be described as a bi-linear function in all subjects, with the intersection point between $S_{1}$ and $S_{2}$ corresponding to the GET. Patients with MM presented lower $S_{1}, S_{2}$ and $S_{T}$ slopes than controls $(P<0.05$; Table 2). However, the betweengroup differences were more prominent in the $S_{2}$ slope compared to $S_{1}$ and $S_{T}$ (mean $\%$ reduction in $\mathrm{MM}$ patients compared to controls $=33.9,17.8$, and $25.2 \%$, respectively). Therefore, the ratio between the $S_{2}$ and $S_{1}$ slopes was significantly lower in patients than controls $(0.87 \pm 0.15$ vs 1.08 $\pm 0.18, \mathrm{P}<0.01)$. In addition, on-exercise $\mathrm{VO}_{2}$ kinetics (MRT), considering either $S_{1}$ or $S_{T}$, was slower in patients than controls $(\mathrm{P}<0.05$; Table 2).

\section{$\Delta \mathrm{VO}_{2} / \Delta \mathrm{WR}$ and functional impairment}

As shown in Figure 2, the overall $\Delta \mathrm{VO}_{2} /$ $\Delta W R$ response (i.e., $S_{T}$ ) was significantly related to peak $\mathrm{VO}_{2}$ in $\mathrm{MM}$ patients, but not in controls. In fact, all patients with $\Delta \mathrm{VO}_{2} /$ $\triangle \mathrm{WR}$ below $8 \mathrm{~mL} \cdot \mathrm{min}^{-1} \cdot \mathrm{W}^{-1}$ had severely reduced peak $\mathrm{VO}_{2}(<60 \%$ predicted) (28). Patients with lower $\Delta \mathrm{VO}_{2} / \Delta \mathrm{WR}$ presented reduced GET $(r=0.73)$ but higher WRcorrected lactate and $\mathrm{MRT}_{\mathrm{T}}-\mathrm{VO}_{2}$ values $(r=0.69$ and $r=0.76$, respectively; $P<$ $0.01)$. Moreover, $\Delta \mathrm{VO}_{2} / \Delta \mathrm{WR}$ was positively related to peripheral muscle endurance in MM patients $(r=0.78 ; P<0.01)$ but not in controls $(P>0.05)$.

\section{Relationship between $\Delta \mathrm{VO}_{2} / \Delta \mathrm{WR}$ and cardiopulmonary responses in MM}

Patients with MM had increased cardiorespiratory responses to the metabolic demands during progressive exercise compared to healthy controls (Table $2 ; \mathrm{P}<0.01$ ) as previously described (16-20). There were significant inverse relationships between $\Delta \mathrm{VO}_{2} / \Delta \mathrm{WR}\left(S_{1}, S_{2}\right.$ and $\left.S_{T}\right)$ and submaximal cardiovascular $\left(\Delta \mathrm{HR} / \Delta \mathrm{VO}_{2}\right)$ and ventilatory $\left(\Delta \mathrm{VE} / \Delta \mathrm{VCO}_{2}\right)$ responses in patients with $\mathrm{MM}(\mathrm{P}<0.05)$. The correlation coefficients, however, were higher for $S_{2}$ than $S_{1}$ and $S_{T}$ $\left(S_{2}=-0.75\right.$ and $-0.69 ; S_{1}=-0.51$ and -0.55 ; $S_{T}=0.60$ and -0.62 , for $\Delta \mathrm{HR} / \Delta \mathrm{VO}_{2}$ and $\Delta \dot{\mathrm{VE}} / \Delta \mathrm{VCO}_{2}$, respectively). 


\section{Discussion}

This study has provided novel evidence that a readily available index of "aerobic efficiency" during ramp-incremental cycle ergometer exercise $\left(\Delta \mathrm{VO}_{2} / \Delta \mathrm{WR}\right)$ is typically reduced in patients with $\mathrm{MM}$, particularly in the supra-GET $\mathrm{S}_{2}$ component. The $\Delta \mathrm{VO}_{2} / \Delta \mathrm{WR}$ was associated with worsening maximal (peak $\mathrm{VO}_{2}$, lactate/WR) and submaximal $\left(\mathrm{VO}_{2} \mathrm{GET}\right)$ markers of aerobic impairment and reduced peripheral muscle performance. In addition, this index was inversely related to submaximal cardiopulmonary stress $\left(\Delta \dot{V} E / \Delta \dot{V} C_{2}\right.$ and $\left.\Delta H R / \Delta \dot{V} O_{2}\right)$, suggesting that these systems adopted a hyperdynamic pattern of response to compensate for an impaired $\mathrm{O}_{2}$ utilization. Our data, therefore, indicate that $\Delta \mathrm{VO}_{2} / \Delta \mathrm{WR}$ may constitute a useful submaximal, effort-independent exercise index for quantification of functional impairment in this patient population.

\section{Aerobic impairment and exercise capacity in MM patients}

For clinical interpretation of $\Delta \dot{V}_{2} / \Delta W R$ during rapidincremental exercise (ramp), it is important to differentiate between this index of aerobic metabolism and the $\mathrm{VO}_{2}-\mathrm{WR}$ relationship in response to constant WR exercise ("economy of cycling"), which is largely independent of fitness or cardiocirculatory dysfunction $(1,2)$. Therefore, $\Delta \mathrm{VO}_{2} / \Delta \mathrm{WR}$ does not directly reflect the efficiency of muscle contraction, but rather the relative increase in aerobic metabolism as power output is increased. In this context, a reduced, but linear, $\Delta \mathrm{VO}_{2} / \Delta \mathrm{WR}$ is thought to represent decreased $\mathrm{O}_{2}$ utilization $(1,2)$. Assuming that patients' ability to increase cardiac output was not impaired (see Study limitations), a lower $\mathrm{C}(\mathrm{a}-\mathrm{v}) \mathrm{O}_{2}$ (i.e., reduced $\mathrm{O}_{2}$ extraction) is the most likely explanation for a reduced $\Delta \mathrm{VO}_{2} / \Delta \mathrm{WR}$ as demonstrated by Taivassalo et al. (19) and, more recently, by Grassi et al. (32) using near-infrared spectroscopy. Considering that $\Delta \mathrm{VO}_{2} / \Delta \mathrm{WR}$ was significantly related to several indicators of aerobic metabolism, this relationship seems to be useful to indicate patients in whom $\mathrm{O}_{2}$ extraction is particularly impaired.

In the present study, we found a strong linear relationship between $\Delta \mathrm{VO}_{2} / \Delta \mathrm{WR}$ and peak $\mathrm{VO}_{2}$ in MM patients, but not in controls (Figure 2). These results are consistent with the notion that the decrease in $\Delta \mathrm{VO}_{2} / \Delta \mathrm{WR}$ in disease conditions associated with impaired $\mathrm{O}_{2}$ delivery or utilization may be severe enough to reduce peak $\mathrm{VO}_{2}$. This has been previously demonstrated by decreasing arterial $\mathrm{O}_{2}$ content in healthy subjects (33) and in chronic cardiovascular disease $(1,6,10)$.

\section{Determinants of the $\Delta \mathrm{VO}_{2} / \Delta \mathrm{WR}$ relationship in MM patients}

Some previous data have demonstrated that a $\Delta \mathrm{VO}_{2} / \Delta \mathrm{WR}$ relationship below the GET $\left(S_{1}\right)$ satisfactorily represents the equivalent steady-state $\mathrm{VO}_{2}$ response

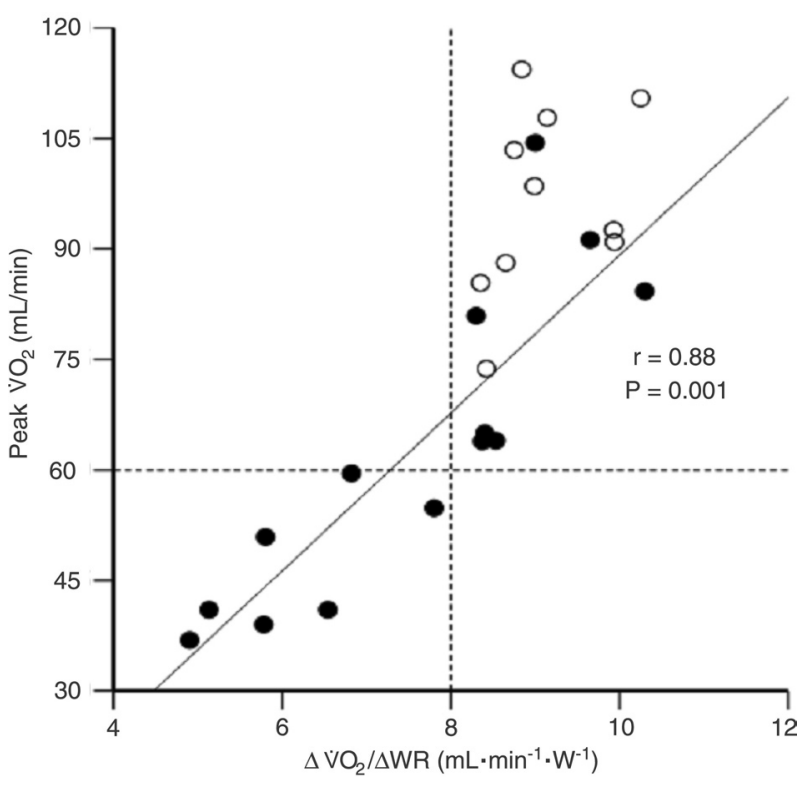

Figure 2. Relationship (Pearson's product-moment correlation) between a submaximal metabolic index of exercise functioning $\left(\Delta \mathrm{VO}_{2} / \Delta \mathrm{WR}\right)$ and peak aerobic capacity (peak $\left.\dot{V O}_{2}\right)$ in patients with mitochondrial myopathy (closed circles) and normal controls (open circles). Note that the lower $\Delta \mathrm{VO}_{2} / \Delta \mathrm{WR}$ values were significantly related to peak $\mathrm{VO}_{2}$ in patients but not in controls. In addition, a $\Delta \mathrm{VO}_{2} / \Delta \mathrm{WR}$ below $8 \mathrm{~mL} \cdot \mathrm{min}^{-1} \cdot \mathrm{W}^{-1}$ was suggestive of severe aerobic impairment in MM patients (peak $\mathrm{VO}_{2}<60 \%$ predicted) (29). $\mathrm{VO}_{2}=$ oxygen consumption; $\mathrm{WR}=$ work rate (power).

$(1,2,5,29)$, even in conditions associated with reduced $\Delta \mathrm{VO}_{2} / \Delta \mathrm{WR}$ (11). For supra-GET exercise, however, the $\mathrm{VO}_{2}$ response provides an imprecise estimate of the total rate of ATP regeneration, since the increased contribution of the anaerobic metabolism would contribute significantly to the overall muscle energetics. Paradoxically, the observed $\mathrm{VO}_{2}$ response is characteristically higher than expected from the sub-GET $\mathrm{VO}_{2}$-WR relationship due to the development of an "excessive" $\mathrm{VO}_{2}$ response (34). Although the determinants of the so-called "slow component" of the $\mathrm{VO}_{2}$ response remain elusive, much of the extra- $\mathrm{VO}_{2}$ seems to derive from the exercising muscles $(\sim 80 \%)$, probably due to progressive recruitment of less efficient type II fibers (4). In fact, the greater increase in $S_{2}$ relative to $S_{1}$ has been found in subjects with a high percentage of type II fibers and at high pedal rates (5).

In the present study, we confirm previous observations that $S_{2}$ is steeper than $S_{1}$ in normal subjects, probably reflecting the contribution of the $\mathrm{VO}_{2}$ slow component $(2,3,5,29)$. This pattern, however, contrasted with that found in patients with MM who showed a consistently lower $S_{2} / S_{1}$ ratio at the same pedaling rate compared to normal subjects. These results were not due to a faster rate of work rate incrementation in patients as the ramp duration did not differ between patients and controls. Although muscle fiber 
typing was not performed in the present study, a selective reduction in the type II fiber population could be related to this phenomenon and/or MM patients may have an impaired ability to recruit these fibers $(35,36)$. Alternatively, the deleterious heteroplasmic mtDNAalterations may have equally affected type I and type II fibers (12). In addition, it should be recognized that some of the mechanisms involved in the $\mathrm{VO}_{2}$ slow component might be linked to lactate production and/or metabolism. Considering, therefore, that the anaerobic contribution (and lactate release) to muscle metabolism is increased in these patients since early exercise $(16,19)$, the increase in lactate (and $\mathrm{VO}_{2}$ ) above the GET, compared to sub-GET, exercise may have been less abrupt in patients than controls. In this context, it is interesting to note that similar findings (lower $S_{2} / S_{1}$ ) were reported in studies involving patients with chronic heart failure probably due to impaired $\mathrm{O}_{2}$ delivery $(33,37)$. We also cannot rule out the possibility that the supra-GET exercise was associated with lower rates of ATP regeneration and further decreases in $\mathrm{O}_{2}$ utilization. Nevertheless, peak $\mathrm{VO}_{2}$ was particularly related to $S_{2}$, suggesting that the end-exercise $\mathrm{VO}_{2}$ response is strongly influenced by the magnitude of the supra-GET $\mathrm{VO}_{2}$ response in patients with reduced $\Delta \mathrm{VO}_{2} / \Delta \mathrm{WR}$ values.

\section{Ventilatory and cardiovascular responses to incremental exercise in MM}

The precise etiology of the hyperventilatory and hypercirculatory responses to dynamic exercise in MM patients is unknown. Some investigators have postulated a common mechanism for these adjustments with a descending parallel activation of the respiratory and cardiovascular centers in response to afferent stimulation from metabolically sensitive chemoreceptors in peripheral skeletal muscles $(19,38)$. Our data showing a strong relationship between $\Delta \mathrm{VO}_{2} / \Delta \mathrm{WR}$ and cardiopulmonary stress suggest that these abnormalities can be mechanistically linked. Therefore, heightened cardiopulmonary responses could be expected in those patients in whom the intramuscular disturbances were more pronounced and the afferent stimuli were higher, i.e., those with lower $\Delta \mathrm{VO}_{2} / \Delta \mathrm{WR}$. This hypothesis, however, should be more properly investigated in studies evaluating the responses to interventions aimed to improved $\mathrm{O}_{2}$ utilization in these patients. Nevertheless, the increased ventilatory and cardiovascular costs combined with lower $\Delta \mathrm{VO}_{2} / \Delta \mathrm{WR}$ $\left(S_{2}\right)$ seem to indicate that they are not relevant to explain the extra- $\mathrm{VO}_{2}$ related to heavy exercise in MM patients.

\section{Study limitations}

In order to accurately measure the power output, the patients were evaluated during incremental cycle ergometry. Therefore, our results may not be applicable to body-bearing activities, such as walking or running. In addition, although patients were screened at rest for significant cardiovascular disease, stroke volume was not measured during exertion. Consequently, we cannot be sure that our patients were "hypercirculatory" as low stroke volume may have limited any increase in cardiac output. Moreover, $\mathrm{C}(\mathrm{a}-\mathrm{v}) \mathrm{O}_{2}$ was not measured and impaired $\mathrm{O}_{2}$ extraction could only be inferred from noninvasive data. Finally, genetic studies were not performed and we were unable to correlate the physiological abnormalities with mtDNA mutation load on skeletal muscle or the qualitative distribution of type fibers (39).

In conclusion, our results indicate that a readily available, effort-independent submaximal index of aerobic dysfunction during ramp-incremental exercise $\left(\Delta \mathrm{VO}_{2} / \Delta \mathrm{WR}\right)$ is severely reduced in patients with $\mathrm{MM}$, being related to increased functional impairment and higher HR and ventilatory responses related to metabolism. This relationship, therefore, should be routinely reported in cardiopulmonary exercise testing evaluations and clinically valued in this patient population.

\section{Acknowledgments}

Research supported by FAPESP. A.C. Gimenes is a Master's graduate student supported by a CAPES fellowship program. L.E. Nery and J.A. Neder are Established Investigators (level II) of CNPq.

\section{References}

1. Hansen JE, Sue DY, Oren A, Wasserman K. Relation of oxygen uptake to work rate in normal men and men with circulatory disorders. Am J Cardiol 1987; 59: 669-674.

2. Hansen JE, Casaburi R, Cooper DM, Wasserman K. Oxygen uptake as related to work rate increment during cycle ergometer exercise. Eur J Appl Physiol Occup Physiol 1988; 57: $140-145$

3. Zoladz JA, Duda K, Majerczak J. Oxygen uptake does not increase linearly at high power outputs during incremental exercise test in humans. Eur J Appl Physiol Occup Physiol 1998; 77: 445-451.

4. Barstow TJ, Jones AM, Nguyen PH, Casaburi R. Influence of muscle fiber type and pedal frequency on oxygen uptake kinetics of heavy exercise. J Appl Physiol 1996; 81: 16421650.

5. Jones AM, Campbell IT, Pringle JS. Influence of muscle fibre type and pedal rate on the $\mathrm{VO}_{2}$-work rate slope during ramp exercise. Eur J Appl Physiol 2004; 91: 238-245.

6. Itoh H. Oxygen uptake: work rate relationship in patients with heart disease. Med Sci Sports Exerc 1992; 37: 374-380.

7. Lewis MI, Belman MJ, Monn SA, Elashoff JD, Koerner SK. The relationship between oxygen consumption and work rate in patients with airflow obstruction. Chest 1994; 106: 366-372. 
8. Sakauchi M, Matsumura T, Yamaoka T, Koami T, Shibata M, Nakamura M, et al. Reduced muscle uptake of oxygen during exercise in patients with systemic lupus erythematosus. J Rheumatol 1995; 22: 1483-1487.

9. Kimura H, Kawagoe Y, Kaneko N, Fessler HE, Hosoda S. Low efficiency of oxygen utilization during exercise in hyperthyroidism. Chest 1996; 110: 1264-1270.

10. Jones S, Elliott PM, Sharma S, McKenna WJ, Whipp BJ. Cardiopulmonary responses to exercise in patients with hypertrophic cardiomyopathy. Heart 1998; 80: 60-67.

11. Toyofuku M, Takaki H, Sugimachi M, Kawada T, Goto $Y$, Sunagawa K. Reduced oxygen uptake increase to work rate increment (DeltaVO $/$ DeltaWR) is predictable by $\mathrm{VO}_{2}$ response to constant work rate exercise in patients with chronic heart failure. Eur J Appl Physiol 2003; 90: 76-82.

12. Edmond JC. Mitochondrial disorders. Int Ophthalmol Clin 2009; 49: 27-33.

13. DiMauro S. Mitochondrial myopathies. Curr Opin Rheumatol 2006; 18: 636-641.

14. Siciliano G, Volpi L, Piazza S, Ricci G, Mancuso M, Murri L. Functional diagnostics in mitochondrial diseases. Biosci Rep 2007; 27: 53-67.

15. Wong LJ. Comprehensive molecular diagnosis of mitochondrial disorders: qualitative and quantitative approach. Ann N Y Acad Sci 2004; 1011: 246-258.

16. Dandurand RJ, Matthews PM, Arnold DL, Eidelman DH. Mitochondrial disease. Pulmonary function, exercise performance, and blood lactate levels. Chest 1995; 108: 182189.

17. Flaherty KR, Wald J, Weisman IM, Zeballos RJ, Schork MA, Blaivas M, et al. Unexplained exertional limitation: characterization of patients with a mitochondrial myopathy. $\mathrm{Am} \mathrm{J}$ Respir Crit Care Med 2001; 164: 425-432.

18. Haller RG, Lewis SF, Estabrook RW, DiMauro S, Servidei $\mathrm{S}$, Foster DW. Exercise intolerance, lactic acidosis, and abnormal cardiopulmonary regulation in exercise associated with adult skeletal muscle cytochrome c oxidase deficiency. J Clin Invest 1989; 84: 155-161.

19. Taivassalo T, Jensen TD, Kennaway N, DiMauro S, Vissing $\mathrm{J}$, Haller RG. The spectrum of exercise tolerance in mitochondrial myopathies: a study of 40 patients. Brain 2003; 126: 413-423.

20. Tarnopolsky MA, Raha S. Mitochondrial myopathies: diagnosis, exercise intolerance, and treatment options. Med Sci Sports Exerc 2005; 37: 2086-2093.

21. Wasserman K, Whipp BJ, Casaburi R, Golden M, Beaver WL. Ventilatory control during exercise in man. Bull Eur Physiopathol Respir 1979; 15: 27-51.

22. Neder JA, Nery LE, Peres C, Whipp BJ. Reference values for dynamic responses to incremental cycle ergometry in males and females aged 20 to 80. Am J Respir Crit Care Med 2001; 164: 1481-1486.

23. Fairbarn MS, Blackie SP, McElvaney NG, Wiggs BR, Pare $\mathrm{PD}$, Pardy RL. Prediction of heart rate and oxygen uptake during incremental and maximal exercise in healthy adults. Chest 1994; 105: 1365-1369.
24. Tartaglia MC, Chen JT, Caramanos Z, Taivassalo T, Arnold $\mathrm{DL}$, Argov Z. Muscle phosphorus magnetic resonance spectroscopy oxidative indices correlate with physical activity. Muscle Nerve 2000; 23: 175-181.

25. Baecke JA, Burema J, Frijters JE. A short questionnaire for the measurement of habitual physical activity in epidemiological studies. Am J Clin Nutr 1982; 36: 936-942.

26. Seligman AM, Karnovsky MJ, Wasserkrug HL, Hanker JS. Nondroplet ultrastructural demonstration of cytochrome oxidase activity with a polymerizing osmiophilic reagent, diaminobenzidine (DAB). J Cell Biol 1968; 38: 1-14.

27. Whipp BJ, Davis JA, Torres F, Wasserman K. A test to determine parameters of aerobic function during exercise. J Appl Physiol 1981; 50: 217-221.

28. Beaver WL, Wasserman K, Whipp BJ. A new method for detecting anaerobic threshold by gas exchange. J Appl Physiol 1986; 60: 2020-2027.

29. Neder JA, Nery LE, Castelo A, Andreoni S, Lerario MC, Sachs A, et al. Prediction of metabolic and cardiopulmonary responses to maximum cycle ergometry: a randomised study. Eur Respir J 1999; 14: 1304-1313.

30. Barstow TJ, Jones AM, Nguyen PH, Casaburi R. Influence of muscle fibre type and fitness on the oxygen uptake/power output slope during incremental exercise in humans. Exp Physiol 2000; 85: 109-116.

31. Glantz SA. A method to estimate the point at which two lines intersect from noisy data. Am J Physiol 1990; 259: H1305H1306.

32. Grassi B, Marzorati M, Lanfranconi F, Ferri A, Longaretti M, Stucchi $A$, et al. Impaired oxygen extraction in metabolic myopathies: detection and quantification by near-infrared spectroscopy. Muscle Nerve 2007; 35: 510-520.

33. Ibanez J, Rama R, Riera M, Prats MT, Palacios L. Severe hypoxia decreases oxygen uptake relative to intensity during submaximal graded exercise. Eur J Appl Physiol Occup Physiol 1993; 67: 7-13.

34. Whipp BJ, Mahler M. Dynamics of pulmonary gas exchange during exercise. In: West JB (Editor), Pulmonary Gas Exchange. New York: Academic Press; 1982. p 36-96.

35. Olsen DB, Langkilde AR, Orngreen MC, Rostrup E, Schwartz M, Vissing J. Muscle structural changes in mitochondrial myopathy relate to genotype. J Neurol 2003; 250: 1328-1334

36. Enns GM, Hoppel CL, DeArmond SJ, Schelley S, Bass N, Weisiger K, et al. Relationship of primary mitochondrial respiratory chain dysfunction to fiber type abnormalities in skeletal muscle. Clin Genet 2005; 68: 337-348.

37. Jeppesen TD, Schwartz M, Olsen DB, Vissing J. Oxidative capacity correlates with muscle mutation load in mitochondrial myopathy. Ann Neurol 2003; 54: 86-92.

38. Haller RG, Lewis SF, Cook JD, Blomqvist CG. Hyperkinetic circulation during exercise in neuromuscular disease. Neurology 1983; 33: 1283-1287.

39. Jeppesen TD, Quistorff B, Wibrand F, Vissing J. 31P-MRS of skeletal muscle is not a sensitive diagnostic test for mitochondrial myopathy. J Neurol 2007; 254: 29-37. 